\title{
Performance of mitochondrial DNA mutations detecting early
} stage cancer

John P Jakupciak¹, Samantha Maragh*1, Maura E Markowitz², Alissa K Greenberg5, Mohammad O Hoque ${ }^{3}$, Anirban Maitra3, Peter E Barker ${ }^{1}$, Paul D Wagner ${ }^{4}$, William N Rom ${ }^{5}$, Sudhir Srivastava ${ }^{4}$, David Sidransky ${ }^{3}$ and Catherine D O'Connell ${ }^{6}$

\author{
Address: ${ }^{1}$ Biochemical Science Division, National Institute of Standards and Technology, Gaithersburg, Maryland 20899, USA, ${ }^{2}$ Geo-Centers, Inc, \\ Newton, Massachusetts, USA, ${ }^{3}$ Johns Hopkins University School of Medicine, 720 Rutland Ave, Baltimore, Maryland 21205, USA, ${ }^{4}$ Cancer \\ Biomarkers Research Group, National Cancer Institute, Rockville, Maryland, USA, ${ }^{5}$ Division of Pulmonary and Critical Care Medicine, NYU, \\ School of Medicine, New York, USA and 'Tetracore, Inc, Rockville, Maryland, USA \\ Email: John P Jakupciak - johnjakupciak@verizon.net; Samantha Maragh* - samantha.maragh@nist.gov; \\ Maura E Markowitz - mauraeve@yahoo.com; Alissa K Greenberg - alissa.greenberg@med.nyu.edu; \\ Mohammad O Hoque - mhoque1@jhmi.edu; Anirban Maitra - amaitra1@jhmi.edu; Peter E Barker - peter.barker@nist.gov; \\ Paul D Wagner - wagnerp@mail.nih.gov; William N Rom - william.rom@med.nyu.edu; Sudhir Srivastava - srivasts@mail.nih.gov; \\ David Sidransky - dsidrans@jhmi.edu; Catherine D O'Connell - coconnell@tetracore.com \\ * Corresponding author
}

Published: 3 October 2008

BMC Cancer 2008, 8:285 doi:10.1/86//47|-2407-8-285
Received: 28 April 2008

Accepted: 3 October 2008

This article is available from: http://www.biomedcentral.com//47I-2407/8/285

(C) 2008 Jakupciak et al; licensee BioMed Central Ltd.

This is an Open Access article distributed under the terms of the Creative Commons Attribution License (http://creativecommons.org/licenses/by/2.0), which permits unrestricted use, distribution, and reproduction in any medium, provided the original work is properly cited.

\begin{abstract}
Background: Mutations in the mitochondrial genome (mtgenome) have been associated with cancer and many other disorders. These mutations can be point mutations or deletions, or admixtures (heteroplasmy). The detection of mtDNA mutations in body fluids using resequencing microarrays, which are more sensitive than other sequencing methods, could provide a strategy to measure mutation loads in remote anatomical sites.
\end{abstract}

Methods: We determined the mtDNA mutation load in the entire mitochondrial genome of 26 individuals with different early stage cancers (lung, bladder, kidney) and 12 heavy smokers without cancer. MtDNA was sequenced from three matched specimens (blood, tumor and body fluid) from each cancer patient and two matched specimens (blood and sputum) from smokers without cancer. The inherited wildtype sequence in the blood was compared to the sequences present in the tumor and body fluid, detected using the Affymetrix Genechip ${ }^{\circledR}$ Human Mitochondrial Resequencing Array 1.0 and supplemented by capillary sequencing for noncoding region.

Results: Using this high-throughput method, $75 \%$ of the tumors were found to contain mtDNA mutations, higher than in our previous studies, and $36 \%$ of the body fluids from these cancer patients contained mtDNA mutations. Most of the mutations detected were heteroplasmic. A statistically significantly higher heteroplasmy rate occurred in tumor specimens when compared to both body fluid of cancer patients and sputum of controls, and in patient blood compared to blood of controls. Only 2 of the 12 sputum specimens from heavy smokers without cancer (I7\%) contained mtDNA mutations. Although patient mutations were spread throughout the mtDNA genome in the lung, bladder and kidney series, a statistically significant elevation of tRNA and ND complex mutations was detected in tumors. 


\begin{abstract}
Conclusion: Our findings indicate comprehensive mtDNA resequencing can be a high-throughput tool for detecting mutations in clinical samples with potential applications for cancer detection, but it is unclear the biological relevance of these detected mitochondrial mutations. Whether the detection of tumor-specific mtDNA mutations in body fluidsy this method will be useful for diagnosis and monitoring applications requires further investigation.
\end{abstract}

\section{Background}

The mitochondrial genome is well characterized and is composed of 16,568 base pairs, harboring 37 densely packed genes [1]. The mitochondrial genome has an accelerated mutation rate in comparison to the nuclear genome [2], and DNA repair is less efficient in the mitochondria than in the nuclear genome [3]. This high frequency of mutation and the high copy number of mitochondria per cell suggest that mtDNA mutations may be useful markers for personalized assessment of cancer. Since mitochondrial DNA lacks introns, mutations are likely to accumulate in the coding regions and have biological consequences [4].

Mutations in mitochondrial DNA (mtDNA) have been detected in colorectal, breast, cervical, ovarian, prostate, liver, pancreatic, and lung cancers [5-22]. Recently, the utility of a mtDNA deletion for molecular definition of benign, malignant and proximal to malignant prostate needle biopsies was reported [23]. These mitochondrial mutations may be linked to a field effect [24], which suggests that mutations in the mitochondrial genome may represent sensitive markers for neoplastic transformation [25]. In addition to cancer, mtDNA instabilities have been reported in degenerative diseases [26-29], neurodegenerative diseases [30,31], macular degeneration [32], aging and longevity [28,33-36] and cardiovascular disease [37].

Body fluids such as urine, which can be obtained by noninvasive techniques, are potential sources of biomarkers that are complementary to traditional sources such as serum or plasma [38]. Recent research demonstrated the feasibility of whole mtgenome analysis using nipple aspirate fluid (NAF) for breast cancer detection [39]. MtDNA mutations in the D-loop were also detected in urine sediments from bladder cancer patients [40]. In some cases, urine analysis for DNA mutations is more sensitive than plasma analysis [41].

Using fluorescence-based capillary electrophoresis (CE) sequencing of the full mitochondrial genome and rigorous quality control procedures [42], we confirmed mtDNA mutations in tumors of 5 of 11 (45\%) lung cancer patients [7]. However, traditional automated sequencing is too laborious and lacks adequate resolution to detect mtDNA heteroplasmy that may be required to detect mtDNA from cancerous cells in the presence of normal cells [43,44]. The Affymetrix Genechip ${ }^{\circledR}$ Human Mitochondrial Resequencing Array 1.0 (MitoChip) is faster, less expensive and allows for better resolution of mixtures than CE DNA sequencing. This microarray design provides replicate information within a single chip for the mtDNA coding region, as both forward and reverse strands are tiled in duplicate, resulting in a four-fold coverage for each nucleotide position of the mitochondrial genome. In this study, we compare the mtDNA from both tumor and associated body fluid with respect to that isolated from the patient's blood. mtDNA isolated from blood provides the normal control or germ-line sequence. To verify these results, CE DNA sequencing was performed on the three matched specimens from a subset of four patients.

The majority of previous studies reported tumor mtDNA mutations that were homoplasmic [45]. In contrast, the heightened sensitivity of the MitoChip allows for the detection of heteroplasmies (the condition where mutations coexist with wild-type genomes). Several recent publications have estimated that more than half of mtDNA sequence publications contain errors [46-48], some of which result from mismatched specimens. Consequently, we used STR analysis to ensure that the samples were accurately matched

Most previous studies have examined tumor tissue for mtDNA mutations, we extended this to evaluate the feasibility of using body fluids in proximity to the tumor as a non-invasive method to detect mtDNA mutations. Our results also suggest that mtDNA mutations in body fluids can partially distinguish lung cancer patients from heavy smokers.

\section{Methods \\ Study Subjects}

Specimens were collected from 26 cancer patients from Johns Hopkins University Hospital after informed consent and IRB approval; and 24 non-cancer smoker controls provided blood and sputum from New York University after informed consent and IRB approval. All DNA samples were prepared from cryostat sectioned frozen cancer tissues, which had been freed of non-neoplastic cells by microdissection. Portions of the primary tumor tissue were routinely embedded in optimum cold temperature medium and the frozen specimen block was then 
cut with a cryostat. Initially, two 5 um sections were obtained for hematoxilyn staining and then examined by light microscopy. Sections from the tumor were reviewed carefully and the neoplastic cell content recorded as a percentage of the total cells on a section. Next several $10 \mathrm{um}$ sections are cut and placed in TE9 containing 1\% SDS/ Protenase K overnight. Following overnight incubation, DNA was extracted and precipitated as described previously [49]. Primary tumor samples containing less than $50 \%$ neoplastic cells were further microdissected to enhance the neoplastic cell content. $80 \%$ ethanol was placed over the lightly stained tissue on the slide and nonneoplastic cell containing regions was dissected away from the tumor cells with fine tissue forceps or a 30-gauge needle using an inverted microscope. Free floating cells are then washed off the slide with $80 \%$ alcohol and the remaining regions of neoplastic cells scraped off and processed in buffer. Extracted DNA was stored at $-20^{\circ} \mathrm{C}$. DNA from primary tumors, body fluids and blood was evaluated. For the collection of the sputum, the study subjects inhale normal saline mist and then cough up a specimen. For the collection of the sputum, the study subjects inhale normal saline mist and then cough up a specimen. The sputum is from the airways and contains alveolar macrophages and bronchial epithelial cells. The sputum is processed for protein analysis and cells are separated by centrifugation and then placed in TRIzol ${ }^{\oplus}$. Bronchoalveolar lavage (BAL) is a saline wash introduced into a wedged bronchoscope and BAL cells retrieved in the saline. The cells are spun down and the BAL fluid stored (it contains $1 \%$ of epithelial lining fluid). The BAL cells are kept in TRIzol $^{\oplus}$. Both the sputum and BAL specimens contain alveolar macrophages.

\section{DNA Isolation}

DNA from tumor sections was digested with 1\% SDS/Proteinase $K$, extracted by phenol, chloroform and ethanol precipitated. Tumor samples were obtained from males and females. Samples were collected primarily from early stage (stage IA to IIB) tumors. We received DNA from 3 matched specimen samples from cancer patients. From 9 lung cancer patients, we received DNA from tumor, blood, and BALs (washings). From 4 bladder cancer and 14 kidney cancer patients, we received DNA from tumor, blood, and urine. Diagnosis and staging of patient tumors is provided in Table 1. In one patient sample set, DNA could not be amplified from the blood and the patient set was removed from analysis

Control samples (blood and matched sputum) were from 12 smokers who did not have cancer. Note that the control population were heavy smokers with a subset (6 of

Table I: Cancer cohort: characteristics and number of mtDNA mutations identified

\begin{tabular}{|c|c|c|c|c|c|}
\hline Sample & Age & Diagnosis & Stage & Blood/Tumor & Blood/Body Fluid* \\
\hline Lung I & 54 & SCC & IA & 6 & 1 \\
\hline Lung 2 & 51 & Adenocarcinoma & IA & 3 & $\mathrm{n} / \mathrm{a}$ \\
\hline Lung 3 & 72 & Adenocarcinoma & IA & 2 (D-Loop) & 0 \\
\hline Lung 4 & 70 & BALV CA & IA & 2 & 0 \\
\hline Lung 5 & 77 & SCC & IA & 3 & 0 \\
\hline Lung 6 & 61 & Adenocarcinoma & IIA & 0 & 1 \\
\hline Lung 7 & 73 & NSCLC & IIB & 0 & 0 \\
\hline Lung 9 & 64 & Carcinoid Tumor & IA & I & 1 \\
\hline Bladder I & 86 & TCC & I & 1 & $\mathrm{n} / \mathrm{a}$ \\
\hline Bladder 2 & 53 & SCC & I & 1 & 0 \\
\hline Bladder 3 & 62 & Large Cell Undifferentiated CA & i & 1 & 0 \\
\hline Bladder 4 & 72 & TCC & II & $\mathrm{n} / \mathrm{a}$ & 4 \\
\hline Kidney I & 74 & Renal Cell CA & II & 3 & 0 \\
\hline Kidney 2 & 58 & Renal Cell CA & II/IV & 2 & $\mathrm{n} / \mathrm{a}$ \\
\hline Kidney 3 & 65 & Renal Cell CA & III & 1 & 0 \\
\hline Kidney 4 & 72 & Renal Cell CA & III & 2 & 0 \\
\hline Kidney 5 & 66 & Renal Cell CA & II & 1 & $\mathrm{n} / \mathrm{a}$ \\
\hline Kidney 6 & 52 & Renal Cell CA & $\| / I I I$ & 2 & 1 \\
\hline Kidney 7 & 33 & Renal Cell CA & I & $\mathrm{n} / \mathrm{a}$ & 0 \\
\hline Kidney 8 & 61 & Renal Cell CA & II & 0 & I \\
\hline Kidney 9 & 75 & Renal Cell CA & II & 1 & 0 \\
\hline Kidney 10 & 62 & Renal Cell CA & I & 0 & 1 \\
\hline Kidney II & 21 & Renal Cell CA & II & 0 & 0 \\
\hline Kidney 12 & 44 & Renal Cell CA & I & 0 & 1 \\
\hline Kidney 13 & 59 & Renal Cell CA & $\|$ & I & 0 \\
\hline Kidney 14 & 59 & Renal Cell CA & I & I (D-Loop) & 0 \\
\hline
\end{tabular}

* all lung body fluids were pre-amplified by WGA 
12) having exposure to asbestos, (Table 2). Patients were considered cancer free based upon spiral CT analysis. DNA in TRIzol ${ }^{\circledR}$ Reagent was recovered using the manufacturer's protocol (Invitrogen Corp., Carlsbad, CA).

\section{STR Genotyping}

All samples were genotyped using the PowerPlex ${ }^{\circledR} 16$ System (Promega Corp, Madison, WI) on a 3130xL genetic analyzer with a $36 \mathrm{~cm}$ capillary array and POP4 polymer and analyzed using GeneMapper ${ }^{\circledR} I D$ v3.2 (Applied Biosystems, Foster City, CA (ABI)). Samples were diluted to $0.5-1.0 \mathrm{ng} / \mu \mathrm{L}$ and $1 \mu \mathrm{L}$ of sample was added to a $24 \mu \mathrm{L}$ reaction volume $(18.2 \mu \mathrm{L} \mathrm{H} 2 \mathrm{O}, 2.5 \mu \mathrm{L} 10 \times$ buffer, $2.5 \mu \mathrm{L}$ PowerPlex $^{\circledast} 1610 \times$ primer pair mix, $0.8 \mu \mathrm{L}$ (4 U) AmpliTaq Gold ${ }^{\circledast}$ DNA Polymerase (ABI)), then PCR amplified using published conditions. $1 \mu \mathrm{L}$ of ILS600 internal lane standard and $9 \mu \mathrm{L}$ of $\mathrm{HiDi}^{\mathrm{TM}}$ Formamide (ABI) were added to $1 \mu \mathrm{L}$ of reaction (or $1 \mu \mathrm{L}$ Allelic Ladder Mix, one for each run) then the mix was briefly denatured and chilled to $95^{\circ} \mathrm{C}$ and placed on crushed ice for 3 minutes before each sequencing run. Based on STR typing, two tumor isolated mtDNA samples did not match the blood sample from the same patient, and were excluded from the data comparison.

\section{PCR Amplification- Long PCR}

Three primer sets resulting in amplicons of 5-6.1 kb in length were used to amplify the DNA for hybridization onto the Affymetrix Genechip ${ }^{\circledR}$ Human Mitochondrial Resequencing Array 1.0 [50]. Together the primer sets allowed for full coverage of the mitochondrial genome. Due to low DNA quantity recovered from DNA isolation, all 12 matched controls (bloods and sputums from non cancer individials) and 8 BAL samples were pre-amplified by Whole Genome Amplification as described in our previous study [51] prior to long PCR. Amplification was conducted using the TaKaRa $L A T q^{\mathrm{TM}}$ Polymerase kit. Briefly, for the MitoChip, the mtDNA template (up to 10

Table 2: Control cohort: characteristics and number of mtDNA mutations identified

\begin{tabular}{ccccc}
\hline Sample & Age & Pack-years & Asbestos & Blood*/Sputum* \\
\hline Control I & 53 & 40 & 7 & 0 \\
Control 2 & 61 & 72 & 35 & 0 \\
Control 3 & 53 & 76 & 33 & 0 \\
Control 4 & 43 & 27 & 10 & 0 \\
Control 5 & 67 & 40 & 24 & 3 \\
Control 6 & 37 & 24 & 0 & 0 \\
Control 7 & 59 & 32.25 & 0 & 1 \\
Control 8 & 49 & 72 & 0 & 0 \\
Control 9 & 33 & 29.75 & 0 & 0 \\
Control 10 & 45 & 52 & 0 & 0 \\
Control II & 51 & 97.5 & 0 & 0 \\
Control 12 & 53 & 37 & 4 & 0 \\
\hline
\end{tabular}

* all control bloods and sputums were pre-amplified by WGA $\mu \mathrm{L}), 0.75 \mu \mathrm{L}$ each of forward and reverse primer $(10 \mu \mathrm{M}$ each), $0.5 \mu \mathrm{L}$ polymerase (2.5 U), $5 \mu \mathrm{L}$ LA PCR Buffer with $\mathrm{MgCl}_{2}, 8 \mu \mathrm{L}$ dNTP mix (2.5 mM each dNTP) and $25 \mu \mathrm{L}$ of $\mathrm{H}_{2} \mathrm{O}$ were mixed for a total reaction volume of $50 \mu \mathrm{L}$. Thermal cycling conditions were as follows: pre-amplification denaturation: ( 1 cycle), $94^{\circ} \mathrm{C}$ for $2 \mathrm{~min}$; amplification (30 cycles): $94^{\circ} \mathrm{C}$ for $15 \mathrm{sec}$; annealing and elongation, $68^{\circ} \mathrm{C}$ for $7 \mathrm{~min}$; final elongation ( 1 cycle), $68^{\circ} \mathrm{C}$ for $12 \mathrm{~min} ; 4^{\circ} \mathrm{C}$ hold. None of the bodily fluid samples could be amplified using the three primer pairs, presumably due to quality and/or quantity of mtDNA obtained from these samples. They were successfully amplified using the nine primer pairs previously validated for fluorescent DNA sequencing to provide full sequence coverage of the mitochondrial genome [42]. This required a slight modification in the pooling step of the MitoChip protocol to accommodate nine instead of three amplicons. Each PCR product was visualized on an agarose gel and analyzed for quality and quantity as previously described [17] or by spectrophotometric methods as described in The GeneChip ${ }^{\circledast}$ CustomSeq $^{\circledR}$ Resquencing Array Protocol Version 2.0.

\section{PCR Cleanup: MitoChip}

PCR clean up was conducted using the QIAquick 96 well vacuum plate manifold and protocol [52]. DNAs were eluted in $65 \mu \mathrm{L}$ of DNAse/RNAse free water.

\section{MitoChip protocol}

The GeneChip ${ }^{\circledR}$ CustomSeq ${ }^{\circledR}$ Resquencing Array Protocol Version 2.0 was used with a few modifications. Briefly, either three or nine amplicons representing the patient and normal control mitochondrial genomes were separately pooled at equi-molar concentrations. Three amplicons were generated from primers provided by JHMI and nine from our previous publication [50]. The PCR amplification products were pooled, fragmented, labeled, hybridized, washed, and scanned. The total quantity of DNA applied to the array was $0.62 \mu \mathrm{g}$. Fragmentation of the pooled DNAs was conducted using 0.15 units of Fragmentation reagent $(0.033 \mu \mathrm{L})$ per sample at $37^{\circ} \mathrm{C}$ for 15 minutes followed by $95^{\circ} \mathrm{C}$ for 15 minutes to inactivate. The fragments were labeled with 30 units of TdT at $37^{\circ} \mathrm{C}$ for 90 minutes followed by $95^{\circ} \mathrm{C}$ for 15 minutes. The hybridization cocktail, including the separately prepared control fragments, was hybridized for 16 to 18 hours at $45^{\circ} \mathrm{C}$ rotating at $60 \mathrm{rpm}$. Arrays were scanned on a GeneArray $^{\circledR} 2500$ Scanner or a GeneChip ${ }^{\circledR}$ Scanner $3000 \mathrm{G} 7$ Scanner, and analyzed with GeneChip ${ }^{\circledR}$ DNA analysis (GDAS) and GSEQ softwares.

\section{MitoChip Sequence Interpretation}

Final analysis of all data was conducted using Affymetrix software GCOS v1.4 and GSEQ v4.0. The probe intensities for each mutation reported by the software were exam- 
ined on the forward and reverse stands for every instance of that base position on the chip. Heteroplamy was identified as 2 bases with probe intensities at least $1.75 \times$ the intensity of background for a sequence position. Mutations are defined as instances where the mitochondrial population in the blood for an individual differs from that of the matched sample at a sequence position, such that the base identified in the matched sample is unique and not found as part of the blood mitochondrial population. Mutations (both homoplasmic and heteroplasmic) were confirmed and only reported when the mutation was seen on both strands for locations tiled once on the MitoChip array, and 3 of 4 strands for locations that appear on the chip twice.

PCR Amplification: NIST Fluorescent Sequencing Protocol Twelve samples (3 matched specimens from 4 cancer patients) were sequenced by fluorescent sequencing. Amplification was performed in two steps using two different sets of primers ( 9 matched and 28 matched sets). The second set was needed to obtain amplicons suitable in length for automated fluorescent sequencing. Mitochondrial DNA amplification using the primary (nine primer sets) and the secondary (28 primer sets) nested PCR was previously described [42].

\section{PCR Cleanup: Fluorescent Sequencing}

An enzymatic PCR cleanup protocol was optimized for high-throughput sequencing by enzymatic cleanup using Exonuclease I and Shrimp Alkaline Phosphotase (SAP) (GE Healthcare, Fairfield, CT). To each sample, $1.5 \mu \mathrm{L}$ of Exonuclease I ( $1 \mathrm{U} / \mathrm{uL})$ and $1.5 \mu \mathrm{L}$ of SAP $(10 \mathrm{U} / \mathrm{uL})$ was added, then incubated at $37^{\circ} \mathrm{C}$ for $90 \mathrm{~min}$ followed by 15 min at $72^{\circ} \mathrm{C}$ with a $4{ }^{\circ} \mathrm{C}$ hold. Samples were subsequently quantified using the Caliper AMS 90 protocol previously described [42].

\section{Fluorescent DNA Sequencing}

The non-coding region ( $1000 \mathrm{nt}$ ) for each sample was sequenced using CE DNA sequencing, as the MitoChip contains only the coding region. The PCR amplification conditions were as published [42]. PCR amplification primers selected were reported previously to specifically amplify mitochondrial encoded DNA sequences $[42,53,54]$. Primers contained M13 tags to facilitate DNA sequencing with M13 forward and reverse sequences. Briefly, the blood, tumor, urine, BAL, and sputum mtDNAs were sequenced using the Big Dye ${ }^{\mathrm{TM}}$ Terminator (BDT) version 3.1 cycle sequencing kit (ABI). A one eighth cycle sequencing reaction was used for all sequencing. Each reaction contained $1 \mu \mathrm{L}$ of each of the following reagents: BDT reagent, DNA (3-6 ng/ $\mu \mathrm{L}$ ), M13 primer (forward or reverse; $5 \mathrm{pmol} / \mu \mathrm{L}), 5 \times$ Dilution Buffer (ABI), and $\mathrm{dH}_{2} \mathrm{O}$ to a final volume of $5 \mu \mathrm{L}$. Cycling sequencing conditions for forward primers were as follows: (40 cycles): $96^{\circ} \mathrm{C}$ for $10 \mathrm{sec}$; annealing, $50^{\circ} \mathrm{C}$ for $5 \mathrm{sec}$; elongation, $60^{\circ} \mathrm{C}$ for $4 \mathrm{~min} ; 4^{\circ} \mathrm{C}$ hold. Reverse primers were sequenced using the same protocol, but the annealing temperature was lowered to $37^{\circ} \mathrm{C}$.

The Montage $\mathrm{SEQ}_{96}$ plate (Millipore Corp., Billerica, MA) was used for cleanup following cycle sequencing. Thirty microliters of Wash Solution (Millipore) was added to each well of the cycle sequencing plate. The samples were transferred to the clean-up plate and placed on the vacuum manifold for 5 to 20 minutes or until the wells were dry. A second wash of $30 \mu \mathrm{L}$ Wash Solution was added and vacuumed dry for an additional 5 to $30 \mathrm{~min}$ utes. Once dry, $20 \mu \mathrm{L}$ of Injection Solution (Millipore) was added to each well and the plate was mixed vigorously on a plate shaker for 10 minutes.

Resuspended samples were transferred to a 3100 Optical Plate and diluted with $15 \mu \mathrm{l}$ of HI-DI Formamide (ABI). All separations were performed using the ABI 3130xL Genetic Analyzer using an $80 \mathrm{~cm}$ capillary and POP7 polymer system. Samples were electrokinetically injected (30 seconds, $1 \mathrm{kV}$ ) and separated at $14.6 \mathrm{kV}$. Sequences were aligned using the DNA Star SeqMan II (5.05) program and scanned for polymorphisms and sequence variants.

\section{Statistical Analysis}

To determine the statistical significance of mutation and heteroplasmy rates, probability estimates were compared. To test for equivalence the confidence intervals were evaluated for equality at $95 \%$ confidence. Distribution of mutations with respect to gene length was tested by Chi square.

\section{Results}

In this study, we evaluated the performance of the Affymetrix Genechip ${ }^{\circledast}$ Human Mitochondrial Resequencing Array 1.0 for detecting mutations present in both tumors and body fluids. Sequence differences between the tumor and the germline (blood) and between body fluid and the germline (blood) were reported as mutations. Sequence differences between the germline and the mtDNA reference sequence tiled on the microarray were considered polymorphisms The microarray software used in this study "learns" as the data set increases, allowing for more statistically significant differentiation between "normal" and "mutant" mitochondrial genotypes [55].

We assessed the DNA mutation spectrum of the entire mitochondrial genome from 72 samples obtained from 26 individuals with different early stage cancers (Table 1). Three matched samples from blood, tumor and body fluid were analyzed from each patient. Six specimens were excluded from comparison due to insufficient sample quantity to perform sequencing (BAL 2, bladder urine 1), 
insufficient sample to perform the genotyping analysis (kidney urines 2 and 5) or genotypes that could not confirm the specimen to be from the same patient as the blood (bladder tumor 4 and kidney tumor 7); these are designated n/a in Table 1. For the lung cancers, we analyzed mtDNA from primary tumor, brochoalveolar lavage, and blood. For bladder and kidney cancers, we analyzed mtDNA from tumor, urine, and blood. Control samples (blood and matched sputum) were from 12 smokers who were considered cancer free based upon spiral CT analysis. There is overlap in the alveolar macrophages obtained from the sputum and BALs. As reported previously, the long PCR products required for our MitoChip protocol could not be obtained from many of the clinical samples [50]. We therefore used multiple strand displacement amplification to produce sufficient quantities of DNA for application to the arrays. As reported, the amplified material was not altered during multiple strand displacement amplification, retaining the identical heteroplasmic and homoplasmic sequence variants detected in the clinical specimen.

\section{Mutations detected}

MitoChip analysis of the coding region combined with CE analysis of D-loop regions revealed mutations in tumor and body fluid specimens. Tumor samples revealed 18 of 24 speciemens with mutations (6/8 lung [79\%]; 3/3 bladder [100\%] 9/13 kidney [69\%]), for a preliminary sensitivity of $75 \%$. This is significantly higher than observed in prior studies [7]. These data also identified mutations in patient bodily fluids that differed from peripheral blood in 8 of 22 cancer patients; 3/7 BALs, 1/3 bladder urine and $4 / 12$ kidney urine specimens (Table 1). Samples contained one or more mutation. Two of the twelve (17\%) sputum specimens from heavy smokers without cancer contained one or more mitochondrial mutations (Table 2 ); a preliminary specificity of $83 \%$. One specimen contained 3 mutations and the other contained one mutation. Three of these mutations are silent.

A total of 34 mutations were detected in the tumor specimens. Three of the mutations occurred in the D-loop, while the majority of the mutations were spread throughout the coding region. To evaluate whether statistically significant clustering of mutations was found, Chi square values were calculated to compare the location of mutations with the gene targets represented as a proportion of the entire mtDNA genome. For tumor mutations in all genes a nonrandom clustering was suggested for tRNAs and the ND complex genes. The percentages of mutations found within a gene in relation to the percentage of the genome occupied by that gene are; ND complex: $33.4 \%$ of the mtgenome and $47.1 \%$ of the mutations, tRNA genes: $9.1 \%$ of the mtgenome and $17.6 \%$ of the mutations, rRNA genes: $15.2 \%$ of the mtgenome and $20.6 \%$ of the muta- tions, D-loop: $6.8 \%$ of the mtgenome and $8.8 \%$ of the mutations, CO: $20.8 \%$ of the mtgenome and $2.9 \%$ of the mutations, and CytB: $6.9 \%$ of the mtgenome and $2.9 \%$ of the mutations. There were no mutations detected in the ATPase genes which account for $5.1 \%$ of the mtgenome. Thus, mutations more frequently occurred in specific genes, and were statistically rare in the CO genes. Eleven mutations were detected in the body fluids, and the majority of these were heteroplasmic with all mutations occurring in the coding region. The entire list of mutations detected in this study is shown in Table 3, with only purine and pyrimidine heteroplasmies found.

\section{Heteroplasmy}

The reported limit of detecting mixed bases or heteroplasmies in solid tumors and body fluids using the MitoChip approaches $2 \%$ [50]. We examined the frequency of heteroplasmy in specimens from cancer patients and a control cohort. A total of 202 sequence variants (with respect to the reference sequence) were identified in the mitochondria from the blood of 12 heavy smokers without cancer (Table 4 ); only 7 of these (3.5\%) were heteroplasmic. All seven of these were detected in both blood and sputum and are not haplotype markers. Overall, the rate of heteroplasmy in the control population was quite low; 7 nucleotides in 185,412 nucleotides sequenced, or $0.0038 \%$. The rate of heteroplasmic calls was highest in the tumor DNAs, where $10.5 \%$ of all sequence variants detected (43 in 411 ) were heteroplasmic. In the cancer population, mtDNA heteroplasmies were detected in the blood of 18 of the 26 samples $(69.2 \%)$ a statistically significantly higher heteroplamy rate than observed in, control blood samples where only 4 of the $12(33.3 \%)$ contained one or more heteroplasmies (Table 4).

\section{MitoChip compared with CE DNA Sequencing}

The MitoChip sequencing results were compared to bidirectional fluorescent CE DNA sequencing for the 3 matched specimens from 4 patients, a total of 12 samples (Table 5). The MitoChip and CE DNA sequencing results were $99.996 \%$ identical ( 8 differences in 198,816 nt). The percent sequence coverage for the MitoChip was $95.8 \%$ $(+/-1.4)$, and the percent sequencing coverage for fluorescent $\mathrm{CE}$ sequencing was $97.5 \%(+/-1.2)$. Due to MitoChip's increased sensitivity, more mutations were identified by this method than by CE DNA sequencing. All of the 8 differences were heteroplasmic, and 7 of these were detected by the MitoChip and not CE sequencing. The 7 heteroplasmies detected by the MitoChip were in the following gene complexes: 1 CO I, 1 ATPase, $1 \mathrm{ND}$ (all 3: Thr $\rightarrow$ Ala), 2 tRNA, and 2 silent mutations. The one heteroplasmy detected only by CE DNA sequencing was a silent mutation. 
Table 3: Cancer cohort mutations detected

\begin{tabular}{|c|c|c|c|c|c|c|c|}
\hline & & MitoMap Position & Blood & Tumor & Body Fluid & Gene & amino acid/location \\
\hline \multirow[t]{21}{*}{ Lung } & 1 & $1719 \mathrm{G}$ & $*$ & $r$ & $*$ & I6S rRNA & - \\
\hline & & $2312 \mathrm{~A}$ & $*$ & $*$ & $r$ & I6S rRNA & - \\
\hline & & $3385 \mathrm{~A}$ & $g$ & $r$ & $g$ & NDI & $\mathrm{Ile}>\mathrm{Val}$ \\
\hline & & $3450 \mathrm{C}$ & $\mathrm{t}$ & y & $\mathrm{t}$ & NDI & Pro>Pro \\
\hline & & $3480 \mathrm{~A}$ & $*$ & $r$ & $*$ & NDI & Lys > Lys \\
\hline & & $4901 \mathrm{~A}$ & $g$ & $r$ & $g$ & ND2 & $G \ln >G \ln$ \\
\hline & & $5773 \mathrm{G}$ & $\mathrm{a}$ & $r$ & $\mathrm{a}$ & tRNACys & $\mathrm{T}$ arm \\
\hline & 2 & $3450 \mathrm{C}$ & $*$ & $y$ & $\mathrm{n} / \mathrm{a}$ & NDI & Pro>Pro \\
\hline & & $4580 \mathrm{G}$ & $\mathrm{a}$ & $r$ & $\mathrm{n} / \mathrm{a}$ & ND2 & Met $>$ Met \\
\hline & & $4901 \mathrm{~A}$ & $*$ & $r$ & $\mathrm{n} / \mathrm{a}$ & ND2 & $G \ln >G \ln$ \\
\hline & 3 & $16162 \mathrm{~A}$ & $*$ & $g$ & $*$ & D-Loop & - \\
\hline & & $16284 \mathrm{~A}$ & $*$ & $g$ & $*$ & D-Loop & - \\
\hline & 4 & $10245 \mathrm{~T}$ & $*$ & y & $*$ & ND3 & $\operatorname{Leu}(2)>\operatorname{Leu}(I)$ \\
\hline & & $13856 \mathrm{~T}$ & $*$ & y & $*$ & ND5 & $\mathrm{Leu}_{2}>$ Pro \\
\hline & 5 & 10427 G & $*$ & $r$ & $*$ & tRNAArg & anticodon arm \\
\hline & & $10885 \mathrm{~T}$ & $*$ & $y$ & $*$ & ND4 & Phe $>$ Phe \\
\hline & & II083 A & $*$ & $r$ & $*$ & ND4 & Met $>$ Met \\
\hline & 6 & $8705 \mathrm{~T}$ & $*$ & $*$ & $y$ & ATPase 6 & Met $>\mathrm{Thr}$ \\
\hline & 7 & - & - & - & - & - & - \\
\hline & 9 & $6413 \mathrm{~T}$ & c & c & y & $\mathrm{COI}$ & Asp $>$ Asp \\
\hline & & $11072 \mathrm{~T}$ & $*$ & $y$ & $*$ & ND4 & $\operatorname{Ser}(1)>\operatorname{Pro}$ \\
\hline \multirow[t]{7}{*}{ Bladder } & 1 & $12236 \mathrm{G}$ & $*$ & $r$ & $\mathrm{n} / \mathrm{a}$ & tRNASer & - \\
\hline & 2 & I $2477 \mathrm{~T}$ & $*$ & y & $*$ & ND5 & $\operatorname{Ser}(2)>\operatorname{Ser}(2)$ \\
\hline & 3 & $1193 \mathrm{~T}$ & $*$ & $y$ & $*$ & I2S rRNA & - \\
\hline & 4 & $5169 \mathrm{~T}$ & $*$ & $\mathrm{n} / \mathrm{a}$ & $y$ & ND2 & Trp>Arg \\
\hline & & $6483 \mathrm{C}$ & $*$ & $\mathrm{n} / \mathrm{a}$ & $y$ & $\mathrm{COI}$ & Leu(2)>Phe \\
\hline & & 10668 G & $*$ & $\mathrm{n} / \mathrm{a}$ & $r$ & ND4L & $\mathrm{Ala}>\mathrm{Thr}$ \\
\hline & & $127 \mid 4 \mathrm{~T}$ & $*$ & $\mathrm{n} / \mathrm{a}$ & y & ND5 & $\| l e>l e$ \\
\hline \multirow[t]{20}{*}{ Kidney } & 1 & $841 \mathrm{~A}$ & $*$ & $r$ & $*$ & I2S rRNA & - \\
\hline & & $2731 \mathrm{~T}$ & * & $y$ & $*$ & I6S rRNA & - \\
\hline & & $12139 \mathrm{~T}$ & $*$ & $y$ & $*$ & tRNAHis & acceptor arm \\
\hline & 2 & $1816 \mathrm{G}$ & $*$ & $r$ & $\mathrm{n} / \mathrm{a}$ & I6S rRNA & - \\
\hline & & $3454 \mathrm{G}$ & $*$ & $r$ & $\mathrm{n} / \mathrm{a}$ & NDI & Ala $>$ Thr \\
\hline & 3 & $12477 \mathrm{~T}$ & $*$ & y & $*$ & ND5 & $\operatorname{Ser}(1)>\operatorname{Ser}(2)$ \\
\hline & 4 & $841 \mathrm{~A}$ & $*$ & $r$ & $*$ & I2S rRNA & - \\
\hline & & $11394 \mathrm{~T}$ & $*$ & $y$ & $*$ & ND4 & Leu $(I)>$ Pro \\
\hline & 5 & $12148 \mathrm{~T}$ & $*$ & $y$ & $\mathrm{n} / \mathrm{a}$ & tRNAHis & $\mathrm{D}$ arm \\
\hline & 6 & $1074 \mathrm{G}$ & $*$ & $r$ & $*$ & I2S rRNA & - \\
\hline & & $3244 \mathrm{G}$ & $*$ & $r$ & $*$ & tRNALeu & $\mathrm{D}$ arm \\
\hline & & $14766 \mathrm{C}$ & $\mathrm{t}$ & $\mathrm{t}$ & $*$ & CytB & Ile $>$ Thr \\
\hline & 7 & - & - & $n / a$ & - & - & - \\
\hline & 8 & $6800 \mathrm{~A}$ & $*$ & $*$ & $g$ & $\mathrm{COI}$ & $\mathrm{Val}>\mathrm{Val}$ \\
\hline & 9 & $15283 \mathrm{~T}$ & $*$ & y & $*$ & CytB & Phe $>$ Phe \\
\hline & 10 & $|247| \mathrm{T}$ & $*$ & $*$ & y & ND5 & $\|\mathrm{l}>\| \mathrm{le}$ \\
\hline & 11 & - & - & - & - & - & - \\
\hline & 12 & $127 \mid 4 \mathrm{~T}$ & $*$ & $*$ & $y$ & ND5 & $\| l e>l e$ \\
\hline & 13 & $7148 \mathrm{~T}$ & $*$ & $y$ & $*$ & $\mathrm{COI}$ & Thr $>$ Thr \\
\hline & 14 & $72 \mathrm{~T}$ & $*$ & $\mathrm{a}$ & $*$ & D-Loop & - \\
\hline
\end{tabular}

$*$ : sequence identical to reference sequence

$\mathrm{n} / \mathrm{a}$ : no data available due to insufficient DNA quantity or STR genotyping results

- : no sequence differences between samples or unknown change to gene

$r$ : purine heteroplasmy $(A+G)$

$\mathrm{y}$ : pyrimidine heteroplasmy $(C+T)$

\section{Discussion}

Mitochondrial genomes of 26 cancer patients, mostly with early stage (Stage I or II) disease, and 12 heavy smokers without cancer were fully sequenced using the Mito-
Chip and additionally fluorescent CE sequencing for the D-loop region only. DNAs isolated from blood, primary tumor, and BAL for lung cancer patients, from blood, primary tumor, and urine for bladder and kidney cancer 
Table 4: Percent of heteroplasmy calls out of total number of sequence variants.

\begin{tabular}{lccc}
\hline Genomes sequenced & Number of sequence variants & $\begin{array}{c}\text { Number (\%) of heteroplsmy } \\
\text { sequence variants }\end{array}$ & $\begin{array}{c}\text { Number (\%) of specimens with } \\
\text { heteroplasmy }\end{array}$ \\
\hline $\begin{array}{l}\text { Blood from patients with cancer - } \\
26\end{array}$ & 391 & $27(6.9 \%)^{*}$ & $18(69.2 \%)^{*}$ \\
Tumor - 24 & 411 & $43(10.5 \%)^{*}$ & $18(75.0 \%)^{*}$ \\
BF from patients with cancer - 22 & 293 & $11(3.8 \%)$ & $7(31.8 \%)$ \\
Blood from individuals without & 202 & $7(3.5 \%)$ & $4(33.3 \%)$ \\
cancer - 12 & 206 & $11(5.3 \%)$ & $5(41.7 \%)$ \\
Sputum from individuals without & & & \\
cancer - I2 & & \\
\hline
\end{tabular}

*: Statistically significant difference from non-cancer population and BF

patients and blood and sputum from smokers without cancer were sequenced; in total 96 mtDNA sequences were determined. All samples were genotyped then subsequently haplotyped to ensure that samples sets from the same patient were matched (data not shown).

Twenty-three of twenty-six (7/8 lung cancer [88\%]; 4/4 bladder cancer [100\%] 12/14 kidney cancer [86\%]) patients were found to have mtDNA mutations in either the tumor or body fluid or in both, for an overall incidence of $89 \%$. Three of seven (43\%) BALs from patients with lung cancer and 2 of $12(17 \%)$ sputums from controls (heavy smokers without cancer) had mtDNA sequence variants, which may result from their heavy smoking [56].

It is interesting to note that the body fluid specimens from the cancer patient population contained fewer mutations overall with respect to the tumors (Table 3). However, it was noted that a heteroplasmic mutation was detected in

Table 5: Nucleotide differences between CE and MitoChip microarray sequencing.

\begin{tabular}{|c|c|c|c|c|c|c|}
\hline & & & MitoMap Position & Mitochip & $\mathrm{CE}$ & Conflicts \\
\hline \multirow[t]{9}{*}{ Lung } & 5 & Blood & $6050 \mathrm{~T}$ & $y$ & $*$ & I \\
\hline & & & $10427 \mathrm{G}$ & $r$ & $*$ & \\
\hline & & Tumor & $10885 \mathrm{~T}$ & y & $*$ & 3 \\
\hline & & & $11083 \mathrm{~A}$ & $r$ & $*$ & \\
\hline & & Bal & $6050 \mathrm{~T}$ & $y$ & $*$ & I \\
\hline & 7 & Blood & $10398 \mathrm{~A}$ & $r$ & $*$ & 2 \\
\hline & & & $12406 \mathrm{G}$ & $*$ & $r$ & \\
\hline & & Tumor & - & - & - & - \\
\hline & & Bal & - & - & - & - \\
\hline \multirow[t]{6}{*}{ Kidney } & 3 & Blood & - & - & - & - \\
\hline & & Tumor & $12477 \mathrm{~T}$ & y & $*$ & I \\
\hline & & Urine & - & - & - & - \\
\hline & 14 & Blood & - & - & - & - \\
\hline & & Tumor & - & - & - & - \\
\hline & & Urine & - & - & - & \\
\hline
\end{tabular}

* represents the same base as the reference sequence base

- represents no base differences between samples
3 BALand 3 urine specimens that was not present in the tumor. Additional comparisons between specimens was hampered by the exclusion of sample results due to insufficient sample quality to perform sequencing, insufficient sample to perform the genotyping analysis or genotyping results indicating that the samples were not from the same individual.

The patient cohorts represent a small study and the biological conclusions are therefore provisional pending analysis of larger populations. With regard to incidence of mtDNA mutations in all solid tumors, a greater proportion of lung cancer patients showed a mutation in the tumor compared with kidney and bladder tumor patients. Furthermore, lung cancer patients also showed the highest incidence of mtDNA mutations in bodily fluids (bronchoalveolar lavage), although at a lower incidence than their lung tumors.

An overall summary of the heteroplasmic variation is shown in Table 4. After statistical analysis of these results, it was determined that the tumor samples presented with statistically significantly more heteroplasmies than any of the other populations, including the body fluids from the same cancer patients. Additionally cancer patient blood samples presented with statistically significantly more heteroplasmies than blood from non cancer controls. This suggests the blood samples from these cancer patients do not reflect purely the germline sequence, as heteroplasmic variation has increased in this sample population.

The increase in heteroplasmy is statistically significant, and not considered sample mixup or an artifact in the MitoChip assay. First, as we reported, all samples were initially genotyped then additionally confirmed to be matched after sequencing by mitochondrial haplotyping. Studies conducting MitoChip analysis on manually mixed samples in a dilution series shows the MitoChip assay able to detect sample mixtures without additional false positives in $10 \%$ mixtures and down to $2 \%[43,50]$. As the control samples and BALs were pre amplified by Whole 
Genome Amplificaton (WGA) this must also be considered as a potential source of generating artifacts. In our previous report, we described a MitoChip comparison between pre amplification by (WGA) and genomic DNAs for a subset of the patient cancer and patient non cancer specimens reported in this study. The sequence and mutation profiles for the samples using WGA are reported in this study. In 19 samples compared with and without WGA, there was no significant difference in the sequence obtained; 15 differences were seen in a total of 628,672 tiled positions $(19 \times 16,544$ with and without WGA $)$, and 12 of these samples had no differences [51]. If heteroplasmies resulted from lower specificity of the assay, it is unlikely that identical results would be obtained from separate amplifications (with or without WGA), or be higher in only the cancer patient blood and tumor DNAs.

The origin of observed sequence changes in the mitochondrial genome in cancer remains unclear. Cancer cells develop in a contiguous field of preneoplastic cells that are clonally related to the initial tumor. This study did not detected similar mutations in the body fluids with respect to the tumor. In most samples, at positions of mutation in the tumor, the body fluid sequence matched the mtDNA sequence of the patient's blood sample. This suggests that the body fluid could not sensitively detect the patient's mutations. In 5 patients, heteroplasmic changes were detected in the body fluid that were absent from both patient blood and the tumor samples. The presence of heteroplasmic variance in the body fluid that is absent from the tumor may suggest that systemic oxidative damage maybe occurring.

The D-loop region, which accounts for approximately $6.8 \%$ of the genome, contained $8.8 \%$ ( 3 of 34 ) of the mutations identified in the tumor mtDNAs. Many studies have focused on the short, hypervariable D-loop region, as this region has been reported to have a higher rate of mutation [2]. However, the majority of mutations found in this study were in the coding region, supporting similar findings in more recent studies $[6,11]$. As reported by Maitra [57], the rationale for preferential sequencing of the non-coding region of mtDNA has been the assumption that this portion of the mitochondrial genome is particularly susceptible to the rigors of DNA damage encountered in metabolically active cancer cells. However, his studies and those of others continue to provide evidence that the coding region is at least equally susceptible to DNA alterations in cancer. In as many as 7 of $14(50 \%)$ preneoplastic samples, somatic alterations restricted to the coding region of mtDNA were detected in that study, while two additional cases had only single non-coding Dloop changes in addition to coding region alterations [57].
The other sequence variants were spread throughout the coding region, with clustering in the tRNA and ND genes ( $17.6 \%$ and $47.1 \%$ respectively). The majority of the tRNA mutations were concentrated in the stem region that is under greater selective constraints than loop structures [58]. While an increase in mutations with respect to the ND complex was identified, none of these mutations were found in ND6, a region recently implicated in cancer metastasis [59]. These findings are expected, as the samples in this study were from early stage cancer. Although outside the focus of this investigation, Table 3 shows that certain mutations linked to the ND complex $(3450,4901)$ were uniquely associated with lung cancer, while other mutations linked to 12srRNA (841) and ND5 (12477, 12714 ) genes were associated with urologic cancers. This trend is intriguing but it is premature to speculate on implications for tissue specific markers.

We extend the detection of mtDNA mutations as biomarkers of cancer to the detection of mtDNA mutations in body fluids. The combination of a high-throughput sequencing method and non-invasively collected specimens make this potentially an attractive diagnostic amenable to current clinical infrastructure. The usefulness of detecting tumor-specific mtDNA mutations in body fluids requires further investigation for diagnosis and monitoring applications. The use of urine DNA as a source of markers for cancer detection has increasing support [60]. In general, genomic biomarkers that are not tissue specific may be best applied for early detection of recurrence or the detection of potential risk of a secondary tumor site. It is worthwhile to investigate ways to enrich certain cell types, e.g. bladder cells, in order to provide more information than just the presence of cancer. This could be accomplished with antibody capture methods, such as those applied for other cancer biomarkers [61]. While urine analysis cannot indicate the location of a tumor, use of specific washes or fluids opens the vista for diagnostic applications.

\section{Conclusion}

In summary, our results indicate that mtDNA sequencing with the MitoChip can be a high-throughput tool for detecting mutations in clinical samples with potential utility for cancer detection. In this study, $79 \%$ of lung, $100 \%$ of the bladder and $69 \%$ of the kidney tumors were found to contain mtDNA mutations; however, these values are based on a limited number of specimens. Our results identified more frequent mutations in the coding region than prior studies with mutation clustering in the tRNA and ND complex genes.

MtDNA mutations may be useful biomarkers, because they affect mitochondrial function, but it is currently unclear the biological relevance of these detected mito- 
chondrial mutations. Our data could not fully substantiate that detection and monitoring of the tumor via mtDNA mutation analysis of body fluids could be a practical way to assess some remote cancer sites. Additional studies are needed to identify the most informative collection procedures and collection site proximity to the tumor. Further, larger scale studies of the mitochondrial genome are needed to compare genotype/phenotype associations in order to understand the pathogenic basis of neoplastic and non-neoplastic diseases linked to mitochondrial dysfunction, and to establish the link between clinico-pathological features and mtDNA mutations.

\section{Competing interests}

The authors declare that they have no competing interests.

\section{Authors' contributions}

JPJ, SM, CDO and PEB performed data analysis and drafted the manuscript. SM, MEM, JPJ, and CDO performed the technical lab work. AKG under WNR and $\mathrm{MOH}$ under DS provided the clinical samples. WNR, AM and DS provided clinical expertise. PDW and SS helped with data interpretation and along with PEB provided project leadership. All authors have read and approved this manuscript.

\section{Acknowledgements}

This study was funded by the $\mathrm{NCl}$-EDRN interagency agreements YICN2020, YICN500I-0I and UOI CA86I37. This study was a collaborative effort between the National Institute of Standards and Technology (NIST) and the National Cancer Institute's Early Detection Research Network (EDRN).

Certain commercial equipment, instruments, materials, or companies are identified in this paper to specify adequately the experimental procedure. Such identification does not imply recommendation nor endorsement by the National Institute of Standards and Technology, nor does it imply that the materials or equipment identified are the best available for the purpose.

*Official contribution of NIST; not subject to copyright.

\section{References}

I. Wallace DC: Mitochondrial diseases in man and mouse. Science 1999, 283:|482-|488.

2. Brown WM, George M Jr, Wilson AC: Rapid evolution of animal mitochondrial DNA. Proc Natl Acad Sci USA 1979, 76:1967-197I.

3. Wong LC, Boles RG: Mitochondrial DNA analysis in clinical laboratory diagnostics. Clin Chim Acta 2005, 354: I-20.

4. Penta JS, Johnson RM, Wachsman JT, Copeland WC: Mitochondrial DNA in human malignancy. Mutat Res 2001, 488: I I9-133.

5. Chinnery PF, Schon EA: Mitochondria. J Neurol Neurosurg Psychiatry 2003, 74: I I88-I I99.

6. Polyak K, Li Y, Zhu H, Lengauer C, Willson JK, Markowitz SD, Trush MA, Kinzler KW, Vogelstein B: Somatic mutations of the mitochondrial genome in human colorectal tumors. Nature Genet 1998, 20:29|-293.

7. Fliss MS, Usadel H, Caballero OL, Wu L, Buta MR, Eleff SM, Jen J, Sidransky D: Facile detection of mitochondrial DNA mutations in tumors and bodily fluids. Science 2000, 287(5460):2017-2019.

8. Nomoto S, Yamashita K, Koshikawa K, Nakao A, Sidransky D: Mitochondrial D-loop mutations as clonal markers in multicentric hepatocellular carcinoma and plasma. Clin Cancer Res 2002, 8(2):48I-487.
9. Ha PK, Tong BC, Westra WH, Sanchez-Cespedes M, Parrella P, Zahurak M, Sidransky D, Califano JA: Mitochondrial C-tract alteration in premalignant lesions of the head and neck: a marker for progression and clonal proliferation. Clin Cancer Res 2002, 8:2260-2265

10. Sanchez-Cespedes M, Parrella P, Nomoto S, Cohen D, Xiao Y, Esteller M, Jernomino C, Jordan RC, Nicol T, Koch WM, Schoenberg M, Mazzarelli P, Fazio VM, Sidransky D: Identification of a mononucleotide repeat as a major target for mitochondrial DNA alterations in human tumors. Cancer Res 200 I, 6 I:70I5-70I9.

II. Jones JB, Song JJ, Hempen PM, Parmigiani G, Hruban RH, Kern SE: Detection of mitochondrial DNA mutations in pancreatic cancer offers a "mass"-ive advantage over detection of nuclear DNA mutations. Cancer Res 200 I, 6 I (4): I 299-I 304.

12. Parrella P, Xiao Y, Fliss M, Sanchez-Cespedes M, Mazzarelli P, Rinaldi M, Nicol T, Gabrielson E, Cuomo C, Cohen D, Pandit S, Spencer M, Rabitti C, Fazio VM, Sidransky D: Detection of mitochondrial DNA mutations in primary breast cancer and fine-needle aspirates. Cancer Res 200I, 61 :7623-7626.

13. Chen JZ, Gokden N, Greene GF, Mukunyadzi P, Kadlubar FF: Extensive somatic mitochondrial mutations in primary prostate cancer using laser capture microdissection. Cancer Res 2002, 62:6470-6474.

14. Copeland WC, Wachsman JT, Johnson FM, Penta JS: Mitochondrial DNA alterations in cancer. Cancer Invest 2002, 20:557-569.

15. Jeronimo C, Nomoto S, Caballero OL, Usadel H, Henrique R, Varzim G, Oliveira J, Lopes C, Fliss MS, Sidransky D: Mitochondrial mutations in early stage prostate cancer and bodily fluids. Oncogene 200I, 20:5195-5198.

16. Okochi O, Hibi K, Uemura T, Inoue S, Takeda S, Kaneko T, Nakao A: Detection of mitochondrial DNA alterations in the serum of hepatocellular carcinoma patients. Clin Cancer Res 2002, 8(9):2875-2878.

17. Hibi K, Nakayama H, Yamazaki T, Takase T, Taguchi M, Kasai Y, Ito $K$, Akiyama S, Nakao A: Detection of mitochondrial DNA alterations in primary tumors and corresponding serum of colorectal cancer patients. Int J Cancer 200I, 94:429-43I.

18. Suzuki M, Toyooka S, Miyajima K, lizasa T, Fujisawa T, Bekele NB, Gazdar AF: Alterations in the Mitochondrial Displacement Loop in Lung Cancers. Clin Cancer Res 2003, 9:5636-564I.

19. Booker LM, Habermacher GM, Jessie BC, Sun AC, Baumann AK, Amin M, Lim SD, Fernandez-Golarz C, Lyles RH, Brown MD, Marshall FF, Peteros JA: North American white mitochondrial haplogroups in prostate and renal cancer. J Urol 2006, I 75:468-473.

20. Petros JA, Baumann AK, Ruiz-Pesini E, Amin MB, Aun CQ, Hall J, Lim SD, Issa MM, Flanders WD, Hosseini SH, Marshall FF, Wallace DC: mtDNA mutations increase tumorigenicity in prostate cancer. Proc Natl Acad Sci USA 2005, 102:719-724.

21. Sharma H, Singh A, Sharma C, Jain SK, Singh N: Mutations in the mitochondrial DNA d-loop region are frequent in cervical cancer. Cancer Cell Int 2005, 5:34-40.

22. Mizumachi T, Muskhelishvili L, Naito A, Furusawa J, Fan CY, Siegel ER, Kadlubar FF, Kumar U, Higuchi M: Increased distributional variance of mitochondrial DNA content associated with prostate cancer cells as compared with normal prostate cells. Prostate 2008, 68:408-4I7.

23. Maki J, Robinson K, Reguly B, Alexander J, Wittock R, Aguirre A, Diamandis EP, Escott N, Skehan A, Prowse O, Thayer RE, Froberg MK, Wilson MJ, Maragh S, Jakupciak JP, Wagner PD, Srivastava S, Dakubo GD, Parr RL: Mitochondrial genome deletion aids in the identification of false- and true-negative prostate needle core biopsy specimens. Am J Clin Pathol 2008, I 29:57-66.

24. Dakubo GD, Jakupciak JP, Birch-Machin MA, Parr RL: Clinical implications and utility of field cancerization. Cancer Cell Int 2007, 7:2.

25. Brandon M, Baldi P, Wallace DC: Mitochondrial mutations in cancer. Oncogene 2006, 25:4647-4662.

26. Sidransky D: Emerging molecular markers of cancer. Nat Rev Cancer 2002, 2:210-219.

27. Wallace DC: A mitochondrial paradigm for degenerative diseases and ageing. In: Ageing vulnerability: causes and interventions. Novartis Found Symp 2001, 235:247-263.

28. Melov S, Shoffner JM, Kaufman S, Wallace DC: Marked increase in the number and variety of mitochondrial DNA rearrangements in aging human skeletal muscle. Nucleic Acid Res 1995, 23:4122-4I 26 . 
29. Melov S, Hinerfeld D, Esposito L, Wallace DC: Multi-organ characterization of mitochondrial genomic rearrangements in ad libitum and caloric restricted mice show striking somatic mitochondrial DNA rearrangements with age. Nucleic Acids Res 1997, 25:974-982.

30. Wallace DC, Murdock DG: Mitochondria and dystonia: The movement disorder connection? Proc Natl Acad Sci USA 1999 96: $1817-1819$.

31. Jun AS, Brown MD, Wallace DC: A mitochondrial DNA mutation at nucleotide pair I 4459 of NADH dehydrogenase subunit 6 gene associated with maternally inherited Leber hereditary optic neuropathy and dystonia. Proc Natl Acad Sci USA 1994, 91:6206-6210.

32. Feher J, Kovacs I, Artico M, Cavallotti C, Papale A, Balacco Gabrieli C: Mitochondrial alterations of retinal pigment epithelium in age-related degeneration. Neurobiol Aging 2006, 27:983-993.

33. Melov S, Wallace DC: Mitochondrial DNA rearrangements in aging human brain and in-situ PCR of mtDNA. Neurobiol Aging 1999, 20:565-571.

34. Jazwinski SM: Metabolic control and ageing. Trends Genet 2000, 16:506-5II.

35. Murdock DG, Christacos ND, Wallace DC: The age related accumulation of a mitochondrial DNA control region mutation in muscle, but not brain, detected by a sensitive PNA directed PCR clamping based method. Nucleic Acids Res 2000, 28:4350-4355.

36. Attardi G: Role of mitochondrial DNA in human aging. Mitochondrion 2002, 2:27-37.

37. Ballinger SW: Mitochondrial dysfunction in cardiovascular disease. Free Radic Biol Med 2005, 38: I 278-1295.

38. Verma M, Srivastava S: New cancer biomarkers deriving from NCl early detection research. Recent Results Cancer Res 2003 , 163:72-84

39. Jakupciak JP, Maggrah A, Maragh S, Maki J, Reguley B, Maki K, Wittock R, Robinson K, Wagner PD, Thayer RE, Gehman K, Gehman T, Srivastava S, Ngom A, Dakubo GD, Parr RL: Facile whole mitochondrial genome resequencing from nipple aspirate fluid using MitoChip v2.0. BMC Cancer 2008, 8:95.

40. Parrella P, Seripa D, Matera MG, Rabitti C, Rinaldi M, Mazzarelli P, Gravina C, Gallucci M, Altomare V, Flammia G, Casalino B, BenedettiPanici PL, Fazio VM: Mutations of the D310 mitochondria mononucleotide repeat in primary tumors and cytological specimens. Cancer Lett 2003, 190:73-77.

4I. Goessl C, Muller M, Straub B, Miller K: DNA alterations in body fluids as molecular tumor markers for urological malignancies. Eur Urol 2002, 4I:668-676.

42. Jakupciak JP, Wang W, Markowitz ME, Ally D, Coble M, Srivastava S, Maitra A, Barker PE, Sidransky D, O'Connell CD: Mitochondrial DNA as a Cancer Biomarker. J Mol Diagn 2005, 7(2):258-267.

43. Jakupciak JP, Dakubo GD, Maragh S, Parr RL: Analysis of potential cancer biomarkers in mitochondrial DNA. Curr Opin Mol Ther 2006, 8:500-506.

44. Meierhofer D, Mayr JA, Fink K, Schmeller N, Kofler B, Sperl W: Mitochondrial DNA mutations in renal cell carcinomas revealed no general impact on energy metabolism. Br J Cancer 2006, 94:268-274

45. Zhu W, Qin W, Bradley P, Wessel A, Puckett CL, Sauter ER: Mitochondrial DNA mutations in breast cancer tissue and in matched nipple aspirate fluid. Carcinogenesis 2005, 26: I 45- I52.

46. Salas A, Yao YG, Macaulay V, Vega A, Carracedo A, Bandelt HJ: A critical assessment of the role of mitochondria in tumorigenesis. PLoS Med 2005, 2:e296.

47. Yao YG, Salas A, Bravi CM, Bandelt HJ: A reappraisal of complete mtDNA variation in East Asian families with hearing impairment. Hum Genet 2006, I I 9:505-5I5.

48. Bandelt HJ, Salas A, Bravi CM: What is a 'novel' mtDNA mutation - and does 'novelty' really matter? J Hum Genet 2006 , 5 I:1073-1082.

49. Hoque MO, Lee CC, Carins P, Schoenberg M, Sidransky D Genome-wide genetic characterization of bladder cancer: a comparison of high-density single-nucleotide polymorphism arrays and PCR-based microsatellite analysis. Cancer Res 2003, 63:2216-22.

50. Maitra A, Cohen Y, Gillespie SE, Mambo E, Fukushima N, Hoque MO Shah N, Goggins M, Califano J, Sidransky D, Chakravarti A: The Human MitoChip: a high-throughput sequencing microarray for mitochondrial mutation detection. Genome Res 2004, 14:8|2-819.

5I. Maragh S, Jakupciak JP, Wagner PD, Rom WN, Sidransky D, Srivastava S, O'Connell CD: Multiple strand displacement amplification of mitochondrial DNA from clinical samples. BMC Med Genet 2008, 9:7.

52. Qiagen QIAquick Multiwell Purification Handbook [http:// wwwl.qiagen.com/literature/handbooks/literature.aspx?id=10002]

53. Parr RL, Maki J, Reguly B, Dakubo GD, Aguirre A, Wittock R, Robinson $K$, Jakupciak JP, Thayer RE: The pseudo-mitochondrial genome influences mistakes in heteroplasmy interpretation. BMC Genomics 2006, 7:185

54. Taylor RW, Taylor GA, Durham SE, Turnbull DM: The determination of complete mitochondrial DNA sequences in single cells: implications for the study of somatic mitochondrial DNA point mutations. Nucleic Acids Res 1999, 29:e74-84.

55. Cutler DJ, Zwick ME, Carrasquillo MM, Yohn CT, Tobin KP, Kushak C, Matthews DJ, Shah NA, Eichler EE, Warrington JA, Chakravarti A: High-Throughput Variation Detection and Genotyping Using Microarrays. Genome Res 200I, I I:1913-1925.

56. Prior SL, Griffiths AP, Baxter JM, Baxter PW, Hodder SC, Silvester KC, Lewis PD: Mitochondrial DNA mutations in oral squamous cell carcinoma. Carcinogenesis 2006, 27:945-950

57. Sui G, Zhou S, Wang J, Canto M, Lee EE, Eshleman JR, Montgomery EA, Sidransky D, Califano JA, Maitra A: Mitochondrial DNA mutations in preneoplastic lesions of the gastrointestinal tract: a biomarker for the early detection of cancer. Mol Cancer 2006, 5:73-8I.

58. Ruiz-Pesini E, Wallace DC: Evidence for adaptive selection acting on the tRNA and rRNA genes of human mitochondrial DNA. Hum Mutat 2006, 27:1072-108I.

59. Ishikawa K, Takenaga K, Akimoto M, Koshikawa N, Yamaguchi A Imanishi H, Nakada K, Honma Y, Hayashi J: ROS-generating mitochondrial DNA mutations can regulate tumor cell metastasis. Science 2008, 320:66I-664.

60. Goess C, Mueller M, Straub B, Miller K: DNA alterations in body fluids as molecular tumor markers for urological malignancies. Eur Urol 2002, 4 I (6):668-676.

6I. Hess JL, Atha DH, Xu JF, Highsmith WE Jr: Telomerase activity measurement in magnetically captured epithelial cells: comparison of slab-gel and capillary electrophoresis. Electrophoresis 2004, 25( | 2): | 852-1859.

\section{Pre-publication history}

The pre-publication history for this paper can be accessed here:

\section{http://www.biomedcentral.com/1471-2407/8/285/pre} pub

Publish with Bio Med Central and every scientist can read your work free of charge

"BioMed Central will be the most significant development for disseminating the results of biomedical research in our lifetime. "

Sir Paul Nurse, Cancer Research UK

Your research papers will be:

- available free of charge to the entire biomedical community

- peer reviewed and published immediately upon acceptance

- cited in PubMed and archived on PubMed Centra

- yours - you keep the copyright 